\title{
AS OBJEÇÕES DE ALBRECHT WELLMER À ÉTICA DO DISCURSO E A FILOSOFIA MORAL FUNDAMENTADA EM UMA TEORIA DO RECONHECIMENTO SOCIAL ${ }^{1}$
}

Pablo HOLMES ${ }^{2}$

- RESUMO: Este artigo trata das críticas, elaboradas por Albrecht Wellmer, ao tipo de teoria moral baseada em princípios universalistas. Inicialmente, é abordada sua tentativa de uma reelaboração da própria idéia de universalismo moral, para depois esboçar a radicalidade de sua crítica a qualquer moral universalista. Nesse ponto, a Ética do Discurso de Jürgen Habermas, é que lhe serve de objeto. Por fim, também a partir de Wellmer, apontam-se possíveis alternativas a esse tipo de ética, sobretudo, a formulação de um ponto de vista moral fundamento numa teoria do reconhecimento social.

- PALAVRAS-CHAVE: Universalismo moral, Albrecht Wellmer, Ética do discurso, lutas por reconhecimento.

\section{Introdução}

Albrecht Wellmer é um autor que pode ser associado ao que se chama, convencionalmente, a segunda geração da "Escola de Frankfurt". Segundo ele mesmo, suas reflexões estiveram bastante próximas àquelas que foram as teses fundamentais de Jürgen Habermas e Karl-Otto Apel, as quais ao menos se inspiram, teoricamente, na crítica à modernidade que desde Adorno e Horkheimer animam uma verdadeira "tradição" do pensamento ocidental (cf. Wellmer, 1989). Ao longo de sua obra, no entanto, o que podemos perceber, é que, na prática, ele passa a seguir, gradativamente, um ca-

1 Realizado com apoio do CNPQ.

2 É Mestre em Filosofia e Teoria do Direito pela Universidade Federal de Pernambuco e doutorando em Sociologia na Universität Flensburg, Alemanha. 
minho próprio, em muitos pontos distintos daquele traçado pelos dois autores frankfurtianos. Suas críticas a Apel e Habermas, cada vez menos, podem ser ditas meros "retoques" ou reformulações superficiais. Sobretudo no que diz respeito à filosofia da ciência e à teoria do conhecimento, suas teses se distanciaram radicalmente daquelas relativas à teoria pragmática do discurso (Wellmer, 2001; 1992).

No presente texto, não vamos apreciar, no entanto, ao menos em primeiro plano, as objeções de Wellmer à teoria da verdade habermasiana: aquelas que talvez sejam a raiz de toda a sua crítica posterior. Com efeito, nosso objeto principal é a crítica que ele oferece à Ética do discurso. A partir dessa crítica, analisaremos a sua própria proposta teórica: debruçar-nosemos sobre sua "ética dialógica falibilista", a qual se apóia numa estratégia alternativa de fundamentação para uma moral universalista em relação àquela proposta por Habermas e, em alguma medida Apel.

Hoje, num contexto teórico em que a teoria social crítica e a filosofia social parecem viver o que Honneth e Fraser já chamaram um: "giro teórico para o reconhecimento" (Honneth, 2003b, p.111; Fraser, 2003, p.7-9), é curioso identificar nessa formulação de Wellmer, uma grande capacidade de antecipação. Com efeito, já desde inícios da década de 1980, quando nem mesmo a Ética do Discurso havia ainda ganhado uma elaboração realmente sistemática, ele já realizava uma crítica de viés "hermenêutico" aos seus antecessores que, indicavam a necessidade de revisão do seu idealismo e universalismo exacerbados - ao mesmo tempo remetendo a teoria para a própria dinâmica das relações sociais concretas - sem, contudo, dispensar a dimensão crítica do pensamento. Posicionando-se sob a influência das éticas neo-aristotélicas da faculdade de julgar situacionalmente orienta$\operatorname{das}^{3}$ e das éticas kantianas universalistas, Wellmer procurou, então, associá-las em uma teoria social crítica que não se limitava a apenas apontar o círculo hermenêutico como a origem das relações morais intersubjetivas. Desde a perspectiva de uma dinâmica do reconhecimento social gradativo, compreendida como eliminação do sem-sentido ético, ele quis oferecer uma dimensão normativa às dinâmicas interpretativas segundo a qual os indivíduos, no limiar da modernidade, orientariam sua faculdade de julgar de modo gradativamente universalista e simétrico.

No rastro de suas formulações, autores como Habermas e Günther, defensores ferrenhos da tradição kantiana foram obrigados, muitas vezes, a reformulações radicais de seu pensamento. Mas, além disso, acreditamos que a dimensão fundamental do trabalho de Wellmer esteja na intuição de

3 Para uma definição do que seja neo-aristotelismo: cf. Schnädelbach, 1986. 
que uma teoria social do reconhecimento que leve em conta as relações sociais estabelecidas a partir de interpretações comuns, pode superar as dificuldades do idealismo da Ética do Discurso.

\section{Questões de moral universalista}

Logo de início, Wellmer chama a atenção para uma diferença entre o princípio de generalização e o princípio de universalização que é de profunda relevância para sua compreensão do significado de uma teoria moral. Para ele, o princípio de generalização, entendido por autores como o próprio Habermas (cf. 2003b, p.83-88) como análogo ao princípio da indução das ciências empíricas, não poderia, nesses termos, ser tratado como o próprio princípio moral desde o qual "deduzimos" maneiras de nos conduzir (Wellmer, 1987, p.43 ss; cf. Günther, 2004, p.39-48)

Segundo ele, a operação de "generalização", típica daquele princípio, poria em relevo, nos juízos empíricos ou normativos, apenas um dado da "gramática lógica das palavras que nos servem para formulá-los" (Wellmer, 1987, p.43). Formulado de outra maneira poderíamos dizer que o princípio significaria apenas que se, no caso de juízos baseados em relações empíricas de causalidade, dizemos que "ocorre a, porque ocorre b" e, portanto, "ceteris paribus, $b$ deve ir sempre seguido de a", no caso de juízos normativos, somos levados, da mesma forma, a dizer que, "se alguém deve fazer a porque se dão as condições $b$, todos deverão - ceteris paribus - fazer a" (Wellmer, 1987, p.44). De modo que o princípio de generalização poderia ser dito, portanto, um mero princípio de igualdade, "pois o que ele exige é o tratamento igual de casos iguais" (Wellmer, 1987, p.44), deixando certo encargo de justificação para aquele que trate casos à primeira vista iguais de modo diferente.

Para Wellmer, é verdade que o princípio normativo da igualdade contém já, em certo sentido, uma noção elementar de justiça, a qual se relacionaria com a idéia de imparcialidade na aplicação de normas previamente existentes. Porém, esse "conceito elementar de justiça se demonstra virtualmente inaplicável quando surge a pergunta sobre aquelas normas que definem os standards para o tratamento igual de casos iguais"; em outras palavras, Wellmer assinala que tudo se complica "quando surge a pergunta acerca da justiça das próprias normas" (1987, p.45) que serviriam de precedente para um juízo imparcial baseado em tal princípio. Ele afirma que "quando se trata de fundamentar normas, há que se determinar, entre outras coisas, quais são os standards corretos para o tratamento igual de casos iguais" (1987, p.45). 
A idéia de que os homens tenham de contar com direitos fundamentais de caráter universalista, comumente é associada à idéia de um princípio da generalização, aparece, segundo ele, apenas muito tardiamente na história cultural ocidental. Na verdade, ela teria surgido somente com o advento da concepção moderna de moral e direito, conseqüência da queda das fundamentações tradicionais para as desigualdades entre os homens. Nessa situação, o princípio de generalização passa, cada vez mais, a se confundir com o princípio de universalização, o que é reforçado, por teorias como a kantiana e mesmo a habermasiana, sob um pressuposto que, contudo, não lhe parece comprovado. Para ele, nesse contexto, um princípio como o da generalização, que, em si mesmo, não guarda qualquer chave para uma teoria moral universalista, foi elevado a uma função que estava além de suas próprias possibilidades: a de fundamentar ele mesmo uma filosofia moral da igualdade. Com efeito, já no que se refere a Kant, Wellmer defende que aquilo que é chamado de Fato da Razão não pode ser associado diretamente ao princípio da generalização.

Segundo ele, "o imperativo categórico me exige atuar unicamente segundo máximas as quais possa desejar que se convertam em leis gerais" (Wellmer, 1987, p.47), ou seja, de acordo com aquilo que posso querer que se converta em lei geral e que está presente em mim, como convicção normativa, fazendo-me, portanto, querer que todos ajam da mesma forma. Nesse sentido, e aí consistiria a diferença entre seu conteúdo e aquele de um princípio da generalização, "o imperativo categórico tem de explicar - de modo convincente para a razão - a possibilidade do 'dever ser' ou 'ter que' que sempre subjazem ao conceito de conviç̧ão normativa (Wellmer, 1987, p.48). Por outro lado, o princípio de generalização, tendo um caráter diferente daquele, "não permite caracterizar de maneira inequívoca as normas universalistas frente a outras classes de normas" (Wellmer, 1987, p.48). Na realidade, o imperativo categórico deveria ser dito um princípio de generalização de segunda ordem; um imperativo que não é válido para todos os seres racionais como algo característico do uso semântico da língua - portanto, como um princípio da generalização - mas, na verdade, como um imperativo dirigido à vontade desses seres racionais (Wellmer, 1987, p.48).

Mas esse esclarecimento não é suficiente para Wellmer. A diferenciação entre o princípio da generalização e o princípio da universalidade de normas só faria evidente que não se pode fundamentar de modo trivial - a partir de sua derivação da própria "lógica" da semântica lingüística - um princípio moral tão ambicioso como aquele contido no imperativo categórico. A rigor, Wellmer aponta que, mesmo como princípio de generalização de "segunda ordem", um imperativo categórico teria sérios problemas.

Para ele, com efeito, o teste de universalidade do tipo kantiano é incapaz de apontar peremptoriamente o que sejam normas válidas. Segundo ele, se se 
procedesse a um teste da aceitabilidade em tese de normas positivas de ação, poderia haver máximas contraditórias que pudessem ser, simultaneamente, queridas como generalizáveis por diferentes sujeitos desde um ponto de vista racionalmente fundamentado. Assim, tornar-se-ia, ao menos desde um ponto de vista lógico e puramente "teórico", inviável uma fundamentação universalista de normas a partir da sua aceitação por um ser racional.

Propondo uma possível reformulação do princípio kantiano, para que este se torne mais aceitável e supere o problema da validade simultânea de normas contraditórias, Wellmer afirma que, em verdade, ao realizarmos o teste de universalidade conforme descrito por Kant, aceitamos não a norma positiva que prescreve uma determinada conduta, mas sim a norma que nos resta depois de fazermo-nos claro nosso "não-poder-querer" a generalização de determinada máxima oposta à proibição de certa conduta inaceitável (1987, p.50 s).

Assim, uma máxima como a neminem laedere - que contém o dever de cuidado com o próximo, "proibindo" que de algum modo alguém se aproveite de um terceiro em proveito próprio - tornar-se-ia válida apenas por não ser aceita a máxima geral oposta à sua proibição. Por fim, a máxima resultante de tal estratégia seria "não posso querer que se torne generalizável a máxima que não proíbe o dano a terceiro". Uma asserção que pode parecer confusa, mas que indicaria, segundo Wellmer, uma tentativa de evitar que a máxima "prejudicarei o próximo sempre que for necessário ao meu bem estar" possa ser considerada válida, para algum indivíduo, pelo simples fato de poder ser universalizável ao menos sob seu ponto de vista.

Para ele, para que uma máxima fosse generalizável por ser positivamente aceitável, ou mesmo simplesmente pelo fato de uma máxima oposta a ela não ser totalmente aceitável, seria necessário que existisse realmente uma tal máxima, com o conteúdo efetivamente expresso de acordo com aquilo que se "quer ver" generalizado. Mas não só isso; essa máxima deveria ser a mesma para todos os possíveis sujeitos, com um mesmo resultado em todos os possíveis testes de generalização, orientados a partir do princípio de universalização contido no imperativo categórico.

Bem de outro modo, quando o "não-poder-querer que determinada máxima se torne universal está na minha própria máxima" testada, a sua generalidade seria, assim, independente de outras formulações, podendo ser levada a cabo sem que se tenha a certeza de que a máxima positiva foi efetivamente validada por todos os possíveis implicados (Wellmer, 1987, p.53).

A verdade é que nem mesmo com uma tal reformulação Wellmer parece aceitar uma teoria moral fundada num princípio universalista racional. Afinal, como chama a atenção Günther, essa estratégia de "dedução pela negativa" de normas práticas, parece apenas ser uma tentativa frustrada (2004, p.83) de fugir da necessidade de um teste dialógico acerca da universabilidade de 
uma norma prática - o que o próprio Wellmer admite como necessário para quem quer sustentar um princípio moral universal (1987, p.54, 65).

Esse raciocínio no mínimo instigante e que nos custou já algumas páginas de texto não teria um valor de mera "sugestão". Aliás, seria até mesmo contraproducente e pouco razoável expor o raciocínio sem que ele viesse a servir de modo mais sistemático para o contexto de nossa reflexão. $\mathrm{Na}$ realidade, a sua importância se revela apenas graças às suas conseqüências para uma crítica mais bem elaborada das éticas universalistas de inspiração kantiana.

\section{0 problema das exceções às normas morais}

Para Wellmer, o teste de universalização realizado pela negativa gravaria as normas com um dado situacional voltado para contextos de exceção que uma estratégia como a kantiana não é capaz de oferecer. Segundo ele, isso se tornaria mais claro graças à distinção, não percebida por Kant, entre a generabilidade de máximas e a generabilidade de razões para atuar, as quais são dadas publicamente e dirigem a vida prática em casos de conflito entre as próprias máximas (Wellmer, 1987, p.54 s). Assim, o indivíduo que nega a máxima permissiva de determinada conduta, de acordo com a sua estratégia "negativista", é capaz, não só de indicar a máxima válida resultante, como lei prática, mas também de dar razões para a negativa, já que esta tem de estar referida a situações específicas em que a máxima que não proíbe uma determinada ação não pode ser aceitável (cf. Günther, 2004, p.83). Isso seria deste modo porque, em lugar de um teste realizado "em tese" de acordo com a racionalidade de certa norma, a alternativa "negativista" exigiria que alguém oferecesse à norma sua não aceitação para determinado caso específico.

Evidentemente, Kant não estava interessado em situações de exceção nas quais normas abstratamente válidas, de acordo com sua estratégia de validação positiva, deveriam ser revistas graças a dados extraordinários da realidade que a fariam circunstancialmente injustas. Ele pôde ser tão "rigoroso", ignorando o problema de que certas situações oferecem exceções com as quais as máximas morais teriam de lidar, simplesmente porque excluía qualquer circunstância conseqüencialista de sua ética, que se interessava apenas pela forma imperativa do dever (Wellmer, 1987, p.66). Criticando veementemente tal posição, Wellmer argumenta pela necessária "consideração de exceções", nas condições atuais da filosofia moral.

Primeiramente, ele chama atenção para o fato de que qualquer norma é dotada de um tal grau de vagueza que faria virtualmente impossível sua aplicação direta a qualquer situação. Com efeito, qualquer procedimento de 
"generalização" depende de modo capital da compreensão que os implicados têm da situação diante da qual a norma é testada. Se uma norma é considerada válida em tese, nada garante que, confrontada com uma situação específica, ela se torne completamente inaplicável, sob o risco de se cometer uma flagrante "imoralidade". Um raciocínio que pode ser esclarecido mediante o já conhecido exemplo da norma proibitiva da mentira - absolutamente válida, em tese - mas com sua aplicabilidade problematizada quando, por exemplo, estivéssemos diante de um caso em que tivéssemos de mentir para salvar alguém de uma perseguição flagrantemente injusta.

Essa ressalva de Wellmer quanto ao problema das exceções, pode ser associada às apresentadas também por Habermas. Ele afirma, categoricamente, a "impossibilidade das normas trazerem todas as suas condições de aplicação" (Habermas, 1999b, p.136), apresentando, no entanto, uma proposta teórica que procura conciliar a existência de um princípio universalista de fundamentação com a consideração de circunstâncias situacionais (1999b, p.136-40; 2001b, p.286-90).

De acordo com as formulações de Klaus Günther (Günther, 2004, p.299358), o que Habermas defende é que, mesmo no caso em que a aplicação de uma norma universalizável e válida nos pusesse em apuros, não necessitaríamos duvidar de sua validade ou mesmo revisar seu conteúdo (2001b, p.2879). Pelo contrário, o que ocorreria, em tais casos, seria apenas um conflito aparente, por assim dizer, prima facie, entre normas distintas simultaneamente válidas. No exemplo já citado, em que devêssemos observar a norma "não mentir", mas também não devêssemos prejudicar alguém, poderíamos estar então, diante de um conflito entre a neminem laedere e a norma proibitiva da mentira, ambas moralmente válidas, embora não simultaneamente aplicáveis à mesma situação (Habermas, 2001b, p.288, nota n.6).

A saída proposta, ao invés de indicar para o descarte de uma das normas ou sua especificação por novos procedimentos argumentativos, consistiria apenas na transição de um discurso concentrado na justificação dessas normas de acordo com o princípio do discurso (D), o que nesse caso já poderia ser tomado por realizado, para um discurso acerca da aplicação de normas que determinasse não sua validade em tese, mas, isto sim, sua adequação a determinada situação (cf. Günther, 2004, p.330 ss).

Tais discursos de aplicação, governados pela idéia de adequação deveriam levar em conta, simultaneamente, (a) um esgotamento de todas as situações específicas do caso e (b) o necessário acordo da norma a ser aplicada com a totalidade de outras normas igualmente válidas (Günther, 2004, p.336-58). Ao mesmo tempo, poder-se-ia, a cada passo, retomar discursos de justificação a fim de fundamentar novas normas possivelmente aplicáveis.

A resposta de Habermas para tal problema, no entanto, não parece satisfatória a Wellmer, servindo, exatamente, para uma radicalização do con- 
textualismo situacional de sua ética dialógica. Isso porque ele não crê, de modo algum na viabilidade de qualquer recurso a normas previamente "fundamentadas". Para Wellmer, mesmo princípios prima facie posteriormente "especificados" ou "aplicados" são incapazes de se transformar em normas com relevância prática. Diante de uma nova situação, distinta daquela para a qual a norma foi dada por "justificada", o "princípio específico" teria de ser sempre alterado, numa constante especificação para cada contexto particular. Por fim, parecer-lhe-ia que "a firmeza dos argumentos aduzidos dependeria mais de nossa capacidade para captar a situação concreta que da possibilidade de formulação de princípios de natureza geral" (1987, p.62).

Com efeito, se teremos, em toda e qualquer situação, de realizar um discurso de aplicação com sensibilidade para traços característicos de exceção, qual seria o sentido de ainda falarmos em discursos de fundamentação num sentido como aquele proposto por Habermas?

A necessidade de que as condutas se baseiem em discursos sobre a situação revela que ele pensa termos de tratar, mais do que com normas, com interpretações de situações ao cuidarmos de problemas práticos. Em verdade, deveríamos, segundo ele, em vez de utilizar a palavra "norma" para apontar o resultado de uma discussão prática, utilizar a expressão "modode-atuar-em-situações-de-certo-tipo" (Wellmer, 1987, p.87, 151).

Para ele, por fim, "um princípio como o imperativo categórico não pode nunca operar em um espaço vazio" (Wellmer, 1987, p.65), necessitando de que as interpretações que temos das situações e de nós mesmos preencham os ocos do princípio formal. Essa crítica, proveniente de Hegel, parece ter sido, aliás, o ponto de engate para a tentativa, realizada pela Ética do Discurso habermasiana, de inserir conteúdo em um princípio que, como proposto por Kant, não contava com as interpretações particulares dos indivíduos. Algo que, na visão de Wellmer, pode ser considerado uma tentativa de flexibilizar o rigorismo kantiano sem abrir mão de seu caráter principiológico e formalista fundamental; o que, no entanto, não parece ser realizado verdadeiramente a contento.

Como formulada em sua origem, a crítica hegeliana assinalava que, deixados a sós com um mandamento estritamente formalista, os implicados tenderiam a uma prática voluntarista insensível a contextos de exceção, algo que poderia ser identificado na experiência histórica do "Terror" jacobino, durante a revolução francesa, e no domínio aí ilimitado do racionalismo moral (Habermas, 1999a, p.23 s; 2004, p.54; 218 ss; cf. Taylor, 2005, p.128-41). Para Wellmer, apesar das tentativas de Habermas para contornar esse problema, o idealismo exagerado parece sempre voltar quando a teoria levanta a exigência um tanto arrogante de que possa, de certa forma, apontar o método último de formulação de normas capazes de pautar a ação dos indivíduos. 


\section{A crítica ao caráter contexto-transcendente da Ética do Discurso}

A Ética do Discurso serve a Wellmer como o "outro" de sua própria linha argumentativa. Isso porque ela se propõe a neutralizar os problemas da ética kantiana, sem abrir mão, no entanto, do formalismo principiológico, do normativismo moral e do princípio de fundamentação universalista de normas.

Sua intenção parece ser, exatamente, a de mostrar que, mesmo quando se incluem interpretações na forma de argumentos, com a necessidade de sua aceitação por parte dos implicados, um princípio moral que sirva para fundamentar normas desde um ponto de vista criterial, recairá sempre naqueles problemas referentes à inabilidade de tratar de contextos particulares e dados situacionais contingentes. Suas deficiências mostrariam, por fim, a necessidade de uma filosofia prática que pudesse contar com uma faculdade de julgar sensível às condições de exceção incessantes na história.

Wellmer chama a atenção, nesse contexto, para o fato de que Habermas confunde o princípio da universalização com o princípio da justiça, o qual, este sim, determinaria a validade de normas. Seu princípio moral serviria para ambos os domínios, o do direito, em que se trata da justiça de enunciados normativos sancionados, e o da moral, em que se trata da "ação correta" em determinada situação. E o motivo desta confusão estaria em que a formulação de seu princípio moral trataria, já de antemão, da validade das normas em abstrato.

Observando o princípio habermasiano em sua formulação mais simples, teríamos:

$\mathrm{U}_{1}$ : Toda norma válida deve satisfazer a condição de que as suas conseqüências possam ser avaliadas pelos afetados como no interesse de todos eles. (Habermas, 2003b, p.116)

Como se vê, no desenvolvimento do princípio, pretende-se que a validade é definida como a justificação de uma norma frente ao interesse de todos os implicados, o que, segundo Wellmer, leva-nos a "reformular o dito postulado moral em termos quase-circulares" (1987, p.82):

$\mathrm{U}_{2}$ : Uma norma favorece uniformemente o interesse de todos os afetados por ela se e somente se pode ser aceita sem coerção por todos eles como uniformemente favorável a seus interesses. (Wellmer, 1987, p.82)

Para ele, essa formulação seria "quase circular" - e não realmente circular - por tratar de níveis diferentes da expressão "interesse de todos". O princípio afirmaria, então, primeiramente, que os participantes sabem que de- 
vem buscar o interesse de todos, como o critério formal a determinar a validade da norma, e, logo depois, que o interesse de todos é encontrado na forma de um consenso sem coação. Essa última assertiva, no entanto, levarnos-ia a uma conseqüência deveras interessante (Wellmer, 1987, p.83).

Como sabemos, Habermas dá às normas morais um caráter de correção (validade) análogo àquele que recebem os juízos verdadeiros. Assim, poderse-ia traduzir uma sentença como "deve-se mentir em certas circunstâncias" por "é correto, dado P, fazer X." onde a palavra "correto" teria uma função correlata à palavra "verdadeiro", em expressões dirigidas ao mundo objetivo como "É verdadeiro que p" (Habermas, 2001a, p.99-106; 2003b, p.81 s). Quando associado ao enunciado $\mathrm{U}_{2}$ acima proposto, tal raciocínio levaria à conseqüência última de que a validade de normas - estabelecida como critério da ação moralmente correta - deveria - graças a tal "analogia" - ser deduzida de uma teoria consensual da verdade que serviria tanto para enunciados sobre fatos como para enunciados sobre normas que regulam condutas (Wellmer, 1987, p.86).

Realmente, se refletirmos bem, para Habermas, a associação da questão da validade de normas, própria do direito, com o problema da correção das ações, própria da moral, conteria, em realidade, a pretensão de fundamentar uma teoria moral cognitivista que tivesse como raiz um critério universalista articulado na idéia de consenso.

Nesse ponto, as críticas mais contundentes de Wellmer se dirigem à própria teoria consensual da verdade que serviria de fundamento à Ética do Discurso como teoria moral. Assim, aquilo que, até aqui, foi visto como uma incapacidade prática do princípio moral universalista tratar de contextos específicos de interação, agora, vai ser compreendido em um plano mais abstrato, como uma tendência de "esquecimento" de contextos históricos que está na própria raiz da Ética do Discurso. Algo, aliás, que ela teria em comum também com a ética kantiana.

Se lembramos bem, a tese central de Habermas seria a de que seriam verdadeiras (assim como corretas) as pretensões de validade que fossem alcançadas segundo um consenso sob condições ideais, algo que seria especificado de acordo com regras de argumentação que poderiam ser deduzidas do próprio princípio de universalização (Habermas, 1986, p.127-83; 2003a, p.43 ss). ${ }^{4}$

Contra a suposição de base dessa formulação e dirigindo-se à própria noção de verdade consensual, Wellmer lança argumentos certeiros que, no con-

4 Em vista das críticas de Wellmer, Habermas alterou essa posição no que diz respeito à teoria da verdade epistêmica. No que tange à teoria moral, sua posição não sofreu alterações que possam ser ditas substanciais em relação à formulada em termos da teoria do consenso (cf. Habermas, 2004, p.45-52; 227-65; 267-310). 
texto do nosso trabalho, como já antecipamos na introdução, vão ser aproveitados apenas na medida de sua importância para uma filosofia prática. De modo que, com fins de economia, podemos resumi-los nas seguintes teses:

1) a racionalidade dos consensos não pode ser caracterizada formalmente: A tese central de Wellmer é a de que a racionalidade dos consensos depende da apreciação que fazemos das razões postas em jogo e não do "modo" como o fazemos. Seria, para ele, portanto, um truísmo dizermos que "admitimos como verdadeira uma crença acedida coletivamente, porque as razões ou argumentos nos pareceram evidentes", como parece querer o critério consensual habermasiano. Em realidade, "que eu tenha razões para dar meu consentimento quer dizer que há uma pretensão de validade que julgo como verdadeira" (Wellmer, 1987, p.96) e a verdade de um enunciado jamais se segue da racionalidade do consenso determinado criterialmente, "senão do acerto das razões que eu possa oferecer em favor da pretensão de validade correspondente". Essas razões, aliás, podem ser vistas, posteriormente, como insuficientes, o que não equivaleria a dizer que o consenso anterior não era racional. Com efeito, não seria aceitável dizer que o consenso dos físicos do século XIX acerca da verdade da Mecânica de Newton não era racional), apesar de hoje sabermos que ele não era verdadeiro (Wellmer, 1987, p.96). Um critério formal, portanto, não pode levar em conta o conteúdo das razões, mas apenas as condições ideais de simetria e isenção de coação contidas nas regras propostas por Alexy (Alexy, 2001, p.211 ss) e acompanhadas por Habermas.

2) a racionalidade e a verdade dos consensos não têm porque coincidir: "Assim como não podemos inferir da falsidade de um consenso a falta de racionalidade do mesmo, tampouco podemos inferir a verdade dos consensos da sua racionalidade" (Wellmer, 1987, p.97). Isso é verdade porque racionalidade e verdade "só coincidem desde a perspectiva interna dos implicados" (Wellmer, 1987, p.97). O que é verdadeiro, como já foi dito, só é tido como tal porque creio nas razões aduzidas. Que eu considere algo, racionalmente, como verdadeiro para mim, não pode funcionar como uma razão adicional para a verdade do que é considerado. De outro modo, vernos-íamos remetidos, sempre, "às mesmas razões ou critérios veritativos que já estavam à nossa disposição quando entendemos uma pretensão de validade" (Wellmer, 1987, p.97). Wellmer, argutamente, percebe que a única maneira de inferir a verdade do consenso a partir da sua racionalidade é incluir, entre as condições ideais de fala, o devido discernimento dos envolvidos para a consideração das razões. Mas, dessa forma, mais uma vez, o critério deixaria de ser formal, e nos restaria em aberto a idéia do que seja um "devido discernimento". 
3) o consenso racional não pode consistir em critério para a verdade: Em virtude das críticas de Wellmer Habermas passou a afirmar que o consenso não deve ter um caráter fático, a ser tomado como critério forte para a verdade cotidiana. Em lugar disso, afirma que ele tem apenas um caráter indicativo: seria uma idéia regulativa que nos serve de modelo de racionalidade para as argumentações. O critério poderia advir do próprio conceito de entendimento, como derivado da noção wittgensteiniana de entender-se mediante o seguimento de uma regra. Assim, estaríamos apenas falando de um consenso lingüístico-semântico que não é controlado diretamente em termos racionais por um discurso criterial. Habermas argumenta, no entanto, que mesmo o uso de palavras de acordo com "regras pragmáticas" pode ser revisto por meio de discursos, com a reformulação de trechos tornados problemáticos do mundo da vida social. Nesses termos, o princípio criterial tem de voltar a valer com toda a força, já que ele não pode permitir que os consensos normativos dependam inteiramente das condições de uso de palavras como "bem" ou "correto" para os utentes de determinada língua, sob pena de perder toda a dimensão universalista da sua teoria. Para Wellmer, por fim, o que se vê é apenas uma reformulação cosmética do conceito criterial de verdade consensual, à qual podem ser aplicadas ainda as críticas precedentes (Wellmer, 1987, p.100 s).

O que Wellmer nos mostra é que a idéia de um consenso racional como idéia regulativa faria sempre - e inevitavelmente - referência a um conceito de consenso racional infinito - o qual remontaria as idéias de Apel - que não poderia mais ser questionado mediante razões (Wellmer1987, p.102).

Esse consenso seria parte daquela idéia, proveniente de Peirce, de uma comunidade de cientistas que, projetada no futuro (in the long run), de acordo com condições ideais de diálogo, levaria à concepção de um possível acordo absoluto acerca da objetividade empírica: uma pressuposição tida por Apel como inevitável para todo e qualquer membro de uma comunidade de experimentação (cf. Apel, 2000a, p.213-25; cf. Costa, 2003, p.45-56). ${ }^{5}$

Somente por meio dessa estratégia afastar-se-ia, realmente, a falibilidade do próprio critério formal, como demonstrado nas objeções 1 e 2, garantindo-se a validade do princípio de racionalidade "U" por cima de consensos contextuais e cambiantes do provincialismo lingüístico de formas de vida particulares.

5 Essa posição não deixa de transparecer indiretamente em Habermas (2001b, p.389, 400 ss). E até mesmo não deixa de estar por trás de sua idéia de um reino de fins kantiano como substituto do mundo objetivo no domínio moral e do papel modelar das ações superrogatórias, na formulação mais recente de sua teoria (2004, p.306). 
É verdade que, mesmo para Apel, o consenso infinito não teria de ser algo alcançado faticamente por argumentações reais, já que essas seriam marcadas pela finitude e gravadas de uma inevitável provisoriedade falibilista (Apel, 2000a, p.220-25; 2000b, p.480 ss). Apesar disso, se essa idéia fosse considerada à luz de uma ressalva falibilista que o atingisse na própria condição de "critério", chegaríamos a duas únicas conclusões possíveis, com conseqüências dramáticas para as pretensões da própria teoria do discurso: (1) por óbvio, ela perderia, em suma, qualquer papel criterial de aproximação à verdade e portanto veríamos realmente uma ruptura entre verdade e racionalidade; (2) ou ele poderia persistir como uma "sugestão" de caráter "regulativo", no mesmo sentido do fato da razão kantiano, mas teria de se referir somente a condições ideais de interação as quais estariam necessariamente fora das experiências possíveis em que se entendem indivíduos concretos (Wellmer, 1987, p.104)

Ora, Wellmer observa que a pressuposição de uma comunidade ideal de comunicação fora das condições da experiência possível (2) não faria nada mais que atualizar as intuições kantianas acerca das idéias dialéticas da razão correspondentes, no seu contexto teórico, à noção de númeno - ou coisa em si. No mesmo nível conceitual em que Kant propusera um reino de fins platônico (Kant, 2000, p.303-9), tal pressuposição teria de "fundir a idéia de consenso de uma comunidade ilimitada de cientistas na idéia de uma comunidade ilimitada de interpretação e interação" (Wellmer, 1987, p.111), a única capaz de eliminar "todos os impedimentos à compreensão mútua" que poderiam habitar uma comunidade real de comunicação (Wellmer, 1987, p.112) e que limitariam a própria noção de um consenso realmente verdadeiro.

Isso só seria possível, no que diz respeito a uma discussão ideal entre cientistas, mediante a suposição de que os participantes de uma tal comunidade, em posse de um entendimento ilimitado, poderiam realizar os testes empíricos comprobatórios das verdades em jogo independentemente das condições históricas e hermenêuticas em que estivessem inseridos. Em termos gadamerianos, Wellmer afirma que teria de haver, então, um nivelamento simétrico de todos os horizontes de sentido numa ilimitação total da compreensão mútua (1987, p.114). Algo que levaria, necessariamente, à eliminação das próprias linguagens semanticamente singulares, com suas vaguezas e ambigüidades - óbices contextuais radicais ao entendimento ilimitado. Só assim, um novo sujeito transcendental (travestido de comunidade ideal) poderia haver logrado se instalar, ele mesmo, de modo definitivo e absoluto, na verdade (Wellmer, 1987, p.115).

Aquilo que Kant houvera concebido como idéias regulativas que deveriam ser pensadas em termos de uma dialética da razão, seria então pensado como regulativo transcendental-pragmático materializado num princí- 
pio universalista que tem de recorrer a uma teoria consensual da verdade. As idéias de uma alma imortal, de uma liberdade ilimitada e de Deus ${ }^{6}$ teriam de ressurgir sob outra forma para que pudesse fazer sentido a pressuposição regulativa de uma comunidade ideal de fala. Wellmer, radicalizando ainda mais esse diagnóstico, relembra a interpretação de Adorno de tal circunstância. Para ele, "a generalização de um conceito de verdade absoluta enfocado futuristicamente e situado no ponto limite do absoluto não teria mais remédio que eliminar inclusive a temporalidade histórica" (Wellmer, 1987, p.118). Dramatizando essa idéia, deveríamos dizer que, se fossem válidas as pressuposições acerca de uma comunidade ideal de comunicação, dever-se-iam incluir nela, necessariamente, todos os possíveis participantes de uma comunidade real. Para que ela pudesse ser mesmo aceitável, diante do suposto de um consenso infinito, teríamos mesmo abarcar, como implicados potencialmente efetivos, até mesmo aqueles que já houvessem falecido faz tempo: os defuntos dotados de uma alma imortal. Segundo Wellmer, consciente das implicações de tais suposições, Adorno já havia revelado como tal idéia só poderia ser concebida em termos teológicos, na figura do Juízo Final (Wellmer, 1987, p.118 s). Uma categoria que, no contexto do cristianismo, apresenta-se como uma ruptura final com o fluxo histórico real.

\section{A formulação de uma proposta alternativa: o caminho para uma teoria do reconhecimento}

Para Wellmer, resta claro que as verdades filosóficas, assim como as verdades científicas e morais, estariam sempre destinadas a serem permanentemente redescobertas (1987, p.121). Passado, presente e futuro são os lugares necessários da verdade em que não cabe jamais qualquer fim da história.

Do ponto de vista da teoria moral, essa consideração o leva a querer excluir a inferência de um princípio de universalização desde os próprios pressupostos da argumentação (1987, p.85). Um princípio como "U”, a contar como núcleo da teoria moral, teria, em última análise, de recorrer a um nível contexto-transcendente a ser permanentemente confrontado pelo contextualismo radical das situações em que somos jogados, inevitavelmente, a interpretações de nós mesmos, dos outros e da realidade (Wellmer, 1987, p.129).

6 Essas são as idéias dialéticas da razão em Kant (2000, p.250-53). 
A partir de uma distinção que se torna para ele fundamental entre direito e moral, Wellmer propõe, então, o que chama uma revisão falibilista da Ética do Discurso (1987, p.143). Segundo ele, no que se refere ao campo do direito, as normas teriam realmente um caráter fundamental, pois que aí se deveria sempre contar com a vigência de determinada norma e sua pertinência a um sistema escalonado estabelecido segundo uma organização que regula seus próprios meios de reprodução (Wellmer, 1987, p.136; 141 ss) - nos termos daquela distinção de Hart entre normas primárias e secundárias (1999, p.101-9) Nesse caso, deveríamos recorrer a uma reflexão acerca do problema de "saber-se que norma se aplica a determinado caso", sendo inevitável uma referência a um discurso de aplicação, embora tratado como um recurso prático de nível convencional.

Já no caso da Moral, em que não existe propriamente um sistema normativo vigente nos mesmos termos em que se estrutura o direito positivo (Wellmer, 1987, p.138), o que importaria seriam os juízos, elaborados em situações concretas, formados por meio de argumentações do que deveria ser generalizado naquela situação. Para ele, os conflitos morais se dariam tipicamente como um problema de mediação entre o universal e o particular, algo que, em circunstâncias pós-metafísicas de falibilismo metodológico e perda do dogmatismo tradicionalista de eticidades concretas, só poderia ser levado a cabo no meio representado por argumentações práticas. Porém, longe de se tratar, como para Habermas, da realização de condições ideais de fundamentação da validade, essas "argumentações morais se ocupam quase exclusivamente da interpretação de tramas situacionais de ações e necessidades, assim como da compreensão que agentes e pacientes têm acerca de si mesmos" (Wellmer, 1987, p.145). Para Wellmer, "isso implica que a pergunta sobre se 'nós podemos desejar que a minha máxima se converta em lei geral' vai ser mais ou menos equivalente à pergunta sobre 'se minha análise da situação, meu auto-entendimento e minhas interpretações são adequados, acertados ou verazes' " em vista dos conflitos práticos em jogo (1987, p.145).

Os discursos de argumentação levados ao cabo como discursos interpretativos poderiam, então, de acordo com essa sua reformulação da discussão prática, ser definidos a partir de dois níveis (Wellmer, 1987, p.146).

O primeiro nível teria uma matriz explicitamente coletiva. Aí, os objetos de interpretação deveriam ser referidos a possíveis revisões das concepções e auto-entendimentos sociais vigentes. Algo que, no contexto da modernidade associar-se-ia à noção de uma crescente abrangência de todos os implicados em uma sociedade particular. Assim, a revisão da compreensão que as sociedades modernas ocidentais teriam, por exemplo, acerca da homossexualidade, do papel das mulheres, acerca da educação, do aborto, etc., poderiam muito bem servir de paradigma para esse proces- 
so de revisão das interpretações socialmente dominantes. No seu desenrolar, veríamos algo que se assemelha àquilo que as éticas kantianas entendem como uma moral universalista (Wellmer, 1987, p.145).

Com efeito, é certo que mesmo concepções universalistas principiológicas mais radicais tiveram perspectivas profundamente excludentes e limitadas acerca do homossexualismo, das mulheres ou mesmo acerca dos jovens (cf. Günther, 2004, p.88). Tal circunstância, segundo Wellmer, deveria nos fazer pensar em que as concepções morais da sociedade estão, na verdade, enraizadas em matrizes coletivas de interpretação, cujas revisões "não se levam a cabo apenas por argumentações, senão sob a pressão de uma luta por reconhecimento e sob a influência de novas experiências" (grifo nosso) (Wellmer, 1987, p.146). O resultado desses processos seria tanto uma nova forma de falar sobre as questões morais relevantes, "como uma maneira distinta dos próprios implicados se verem a si mesmos e se comportarem quanto a si mesmos" (Wellmer, 1987, p.147).

Como afirmou Günther, apesar de Wellmer aparentemente caminhar no sentido de uma ética aristotélica, diferencia-se desse tipo de posição exatamente "por ater às argumentações práticas um elemento universalista, vinculando o juízo sobre a correção moral de uma ação à sua potencial nãogeneralização de uma prática comum" (Günther, 2004, p.93). Se isso é verdade, é fato também que tal universalismo seria uma circunstância típica de sociedades especialmente caracterizadas por uma inclusão ampliada de seus membros como agentes morais dignos de consideração. Algo que, no seu entender, dependeria do pressuposto de que lutas por reconhecimento articuladoras de revisões interpretativas das bases normativas de julgamento moral levassem as sociedades a um estágio em que os sem-sentidos relativos a considerações assimétricas dos atores sociais fossem gradativamente expulsos das argumentações morais (Günther, 2004, p.98). Para Wellmer, "os processos coletivos de aprendizado consistiriam em uma ampliação das relações de reconhecimento mútuo causada por uma deterioração crítica das matrizes de interpretação e atitudes socialmente arraigadas" (1987, p.147). Um processo que não pode ser confundido "com uma aproximação a um ideal", pois que "o princípio do progresso moral não consiste em um aperfeiçoamento do sentido, senão em uma supressão do semsentido" (Wellmer, 1987, p.147).

Por seu turno, o segundo nível das argumentações interpretativas diria respeito à formulação de juízos morais em situações complexas de conflito moral. Ou seja, tratar-se-ia do problema típico do julgamento prático de conflitos morais, um ponto em que Wellmer radicaliza sua tese acerca da impossibilidade de fundamentação de normas morais em tese por um princípio moral. Sua posição, realmente de matiz neo-aristotélica é a de que o princípio moral, ao invés de fundamentar normas, serve para fundamentar, 
com referência a interpretações dependentes das auto-compreensões dos agentes, modos de atuar que não podem ser generalizados por qualquer operação lógica para além da situação em que é posto em jogo (Wellmer, 1987, p.149 s).

Seu argumento fundamental é o de que as exceções sempre recorrentes no fluxo histórico dos acontecimentos jamais poderiam ser subsumidas sob regras gerais, pois isso seria simplesmente exigir que houvesse condições ilimitadas de entendimento que fugiriam as inexoráveis incongruência de expectativas fundadas em uma corrente inesgotável de interpretações divergentes no curso da história. Assim, teríamos, a rigor, uma inevitável inutilidade de quaisquer regras que quisessem valer, ao menos no campo da moralidade, como guias fixos para a prática, pois que, a rigor, tais regras, para serem utilizadas, teriam de ser sempre reelaboradas de acordo considerações situacionais (Wellmer, 1987, p.150).

Para Wellmer, um juízo sobre a generalidade ou não de maneiras de atuar em situações só poderia dizer respeito a interpretações de casos concretos. De modo parecido com Honneth (2003, p.186 s ), ele parece entender as lutas por reconhecimento como processos que podem tomar direções argumentativas também in casu, quando são realizadas em favor da prioridade de certo ponto de vista que consiga eliminar exclusões injustificáveis de um ator moral como apto a fazer contar sua própria interpretação da situação.

De um modo geral, o que podemos ver é que Wellmer não abre mão, em nenhum dos dois níveis dessa sua moral falibilista, de uma tendência normativa para o universalismo contida, de modo velado, nessas lutas contra os "sem-sentidos" morais. Evidentemente, ele parece querer buscar uma saída que apóie o universalismo moral sem que se necessite recorrer a um princípio universalista apoiado em suposições idealistas. Certamente, seu conceito de lutas por reconhecimento social não é elaborado de modo suficientemente diferenciado. Parece mesmo que sua atenção está voltada mais para a crítica ao kantismo moral que à elaboração de uma alternativa teórica viável. Ainda assim, podemos perceber que, da sua crítica, exsurgem sugestões claras acerca das possibilidades de uma teoria do reconhecimento social para a construção de uma teoria moral que não se obrigue a manter um flerte com um mundo das idéias fora da história efetiva.

\section{Considerações finais}

As críticas de Wellmer nos levam a conclusões bem interessantes. Sua acusação, dirigida à Ética do Discurso, de que o idealismo contido na estratégia de fundamentação universalista de normas pode levar a conseqüências que podem ser ditas, no mínimo, contra-intuitivas e, no máximo, me- 
tafísicas, mostrou-nos que não é prescindível uma boa dose de suspeita às estratégias de dedução transcendental da moral.

Aparentemente, as suposições contidas nessa tradição idealista poderiam nos levar a um olvidamento do tempo no interior da vida prática e mesmo de sua dinâmica essencialmente histórica. Um tipo de problema que, aliás, em outros contextos teóricos, já foi identificado com o próprio nascedouro das próprias filosofias ontológicas e da idéia de atemporalidade do pensamento verdadeiro (Theunissen, 1992, p.3-28). Essa "relação perigosa", com efeito, fê-nos até mesmo remontar às dimensões teológicas com que toda metafísica tem de contar talvez até mesmo exatamente por ter sua origem vinculada a uma pré-história religiosa (cf. Cassirer, 1978, p.89).

Dessa crítica radical emergiu a idéia de um progresso moral estimulado por lutas por reconhecimento que não se dirigem necessariamente a pressuposições estáticas da linguagem como critérios transcendentes de mediação moral. Essas idéias são as mesmas que levaram outros autores a criticar as tentativas da teoria do discurso de fundamentar uma teoria moral, ao modo kantiano, baseada em pressuposições da linguagem, sejam elas resultado de uma investigação ontogenética, seja o resultado de um "postulado" pragmático.

É certo que Habermas sempre esteve atento a necessária conexão entre os pressupostos ideais de sua ética universalista e as circunstâncias cambiantes da realidade histórica, que deve ser incluída até mesmo no processo de justificação da própria teoria (cf. Benhabib, 1992, p.39-59). Sua teoria da evolução social é a tentativa mais clara de realizar tal empreendimento. Por outro lado, mesmo com um deflacionismo fundamentalista de sua parte, restam erguidos, na forma de um princípio universalista, pressuposições problemáticas que talvez só possam ser resolvidas a partir de uma teoria do reconhecimento social desenvolvida no medium representado pelas lutas dos implicados em processos de desrespeito e humilhação por aquilo que Wellmer chama uma "eliminação dos sem-sentido" na forma de uma ampliação universalista da inclusão individual.

HOLMES, Pablo. Albrecht Wellmar's objections to Discourse Ethics and the moral philosophy based upon a theory of social recognition. Trans/Form/Ação, (São Paulo), v.31(1), 2008, p.177-196.

- ABSTRACT: This article approaches the Albrecht Wellmer's critic to moral theories which are based on universalistic principles. Our starting point is his attempt to review the very idea of moral universalism. Afterwards, we lean over his radical critics to all kinds of principiological moral universalism, whose main example, on his theoretical context, is the Jürgen Habermas's Ethic of Discourse. 
Finally, we try to grasp some possible alternatives, overall the possibility of elaboration of moral theory on the basis of a theory of social recognition.

- KEYWORDS: Moral universalism, Albrecht Wellmer, Ethic of Discourse, struggles over recognition.

\section{Referências bibliográficas}

ALEXY, Robert. Teoria da argumentação jurídica: a teoria do discurso racional como teoria da justificação jurídica. São Paulo: Landy, 2001.

ALVES, Cleber Francisco. Justiça e Racionalidade Prática - reflexões a partir da obra de Alasdair MacIntyre. In: MAIA, Antonio Cavalcanti et alli (Orgs.). Perspectivas atuais da filosofia do direito. Rio de Janeiro: Lumen Juris, p.135-52, 2005.

APEL, Karl-Otto. Cientificismo ou hermenêutica transcendental. In: Transformação da Filosofia II: Filosofia Analítica, Semiótica, Hermenêutica. São Paulo: Loyola, p.213-25, 2000a.

APEL, Karl-Otto. O a priori da comunidade de comunicação e os fundamentos da ética. In: Transformação da Filosofia II: o apriori da comunidade de comunicação. São Paulo: Loyola, p.407-91, 2000b.

BENHABIB, Seyla. Autonomy, Modernity, and Community: Communitarianism and Ciritical Social Theory in Dialogue. In: HONNETH, Axel et alli (Orgs.). Culturalpolitical interventions in the unfinished project of enlightenment. Cambridge: MIT, p.39-59, 1997.

CASSIRER, Ernst. Linguagem e Mito. São Paulo: Perspectiva, 1978

COSTA, Regenaldo da. Ética do Discurso e verdade em Karl-Otto Apel. Belo Horizonte: Del Rey, 2003.

GÜNTHER, Klaus. Teoria da argumentação no direito e na moral: justificação e aplicação. São Paulo: Landy, 2004.

KANT, Immanuel. Crítica da Razão Pura. São Paulo: Abril, 2000.

HART, Herbert. O conceito de direito. Lisboa: Calouste Gulbenkien, 1999.

HABERMAS, Jürgen. Verdade e justificação: ensaios filosóficos. São Paulo: Loyola, 2004.

Teoría de la acción comunicativa, I: racionalidad de la acción y racionalización social. Madrid: Taurus, 2003a.

. Notas programáticas para a fundamentação da Ética do Discurso. In: Consciência moral e agir comunicativo. Rio de Janeiro: Tempo Brasileiro, p.61-141, 2003b.

Teoría de la acción comunicativa, II: Crítica de la razón funcionalista. Madri: Taurus, 2001a.

Facticidad y validez: sobre el derecho y el Estado democrático de derecho en términos de teoría del discurso. Madrid: Trotta, 2001b.

. As objeções de Hegel a Kant se aplicam à Ética do Discurso? In: Comentários à Ética do Discurso. Lisboa: Instituto Piaget, p.13-31, 1999a. 
HABERMAS, Jürgen. Comentários à Ética do Discurso. In: Comentários à Ética do Discurso. Lisboa: Instituto Piaget, p.193-211, 1999b.

Wahrheitstheorien. In: Vorstudien und Ergänzungen zur Theorie des kommunikatives Handelns. Frankfurt sobre o Meno: Suhrkamp, p.127-83, 1986HARE, R.M. Moral Thinking. Oxford: Oxford University Press, 1981.

HONNETH, Axel. Luta por reconhecimento: a gramática moral dos conflitos sociais. São Paulo: 34, 2003.

SCHNÄDELBACH, Herbert. Was ist Neoaristotelismus? In: KUHLMANN, Wolfgang (Org.). Moralität und Sittlichkeit: Das Problem Hegels und die Diskursethik. Frankfurt sobre o Meno: Suhrkamp, p.38-63, 1986.

TAYLOR, Charles. Hegel e a sociedade moderna. São Paulo: Loyola, 2005

THEUNISSEN, Michael. Metaphysic's Forgetfulness of Time: On the controversy over Parmenides, frag. 8,5. In: HONNETH, Axel e alli (Orgs.). Philosophical Interventions in the unfinished project of Enlightenment. Cambridge: MIT, p.3-28, 1992.

WELLMER, Albrecht. Gibt es eine Wahrheit jenseits der Aussagenwahrheit? In: GÜNTHER, Klaus \& WINGERT, Lutz. Die Öffentlichkeit der Vernunft und die Vernunft der Offentlichkeit. Frankfurt sobre o meno: Suhrkamp, p.13-52, 2001.

What is pragmatic of theory of meaning? Variations on the proposition "We understand a speech act when we know what makes it acceptable". In: HONNETH, Axel e alli (Orgs.). Philosophical Interventions in the unfinished project of Enlightenment. Cambridge: MIT, p.171-18, 1992.

Razón, utopía y la dialéctica de la ilustración. Habermas y la Modernidad. Org.: Anthony Giddens et al. Madrid: Cátedra, p.65-109, 1988.

Ética y Diálogo: elementos del juicio moral en Kant y en la ética del discurso. Barcelona: Antropos, 1987. 